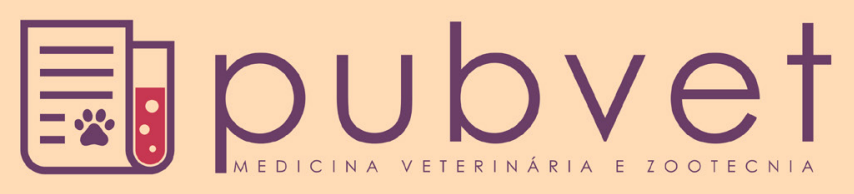

ISSN $1982-126$

HTTP://DX.DOI.ORG/10.22256/PUBVET.V11N4.415-423

\title{
Silagem pré-secada de cereais de inverno em estádio de pré- florescimento: Revisão
}

\author{
Egon Henrique Horst ${ }^{1 *}$, Mikael Neumann ${ }^{2}$, Juliana Mareze$^{1}$, Guilherme Fernando \\ Mattos Leão ${ }^{3}$, André Dochwat ${ }^{2}$ \\ ${ }^{1}$ Universidade Estadual de Londrina, Brasil \\ ${ }^{2}$ Universidade Estadual do Centro - Oeste - Unicentro, Brasil \\ ${ }^{3}$ Universidade Federal do Paraná, Brasil \\ *Autor para correspondência,E-mail: egonhh@yahoo.com.br
}

RESUMO. A produção de silagem pré-secada de melhor custo benefício aliando alta produção, valor nutricional e custo de produção são fundamentais para sobrevivência no sistema produtivo. Nesse contexto, os cereais de inverno ganham destaque por serem excelentes para a oferta in natura, ou seja, em pastejo e terem ainda a possibilidade de conservação de seu excedente. O Sul do país ainda comporta muitas áreas ociosas no período de inverno, áreas onde é cultivado milho, safra após safra, sendo esses, outros pontos favoráveis à confecção desse alimento, aumentando a lucratividade e a rotatividade da mesma. Dentre as culturas de inverno mais utilizadas para o feitio de silagem pré-secada destacam-se a aveia preta (Avena strigosa), aveia branca (Avena sativa), cevada (Hordeum vulgare), trigo (Triticum aestivum), centeio (Secale cereale), e o triticale (X Triticosecale).

Palavras chave: Aveia, bromatologia, forragem conservada, proteína bruta, triticale

\section{Pre-dried silage of winter cereals in pre-flowering stage: A review}

ABSTRACT. The production of pre-dried silage of better cost benefit with high production, nutritional value and cost of production are fundamental for survival in the productive system. In this context, winter cereals are important because they are excellent for the in natura supply, that is, in grazing and also have the possibility of conserving their surplus. The southern part of the country still contains many idle areas in the winter period, areas where maize is grown, harvest after harvest, and these are other favorable points in the preparation of this food, increasing its profitability and its rotation. Among the winter crops most used for the pre-dried silage species are: oats (Avena strigosa), white oats (Avena sativa), barley (Hordeum vulgare), wheat (Triticum aestivum), rye (Secale cereale), and triticale (X Triticosecale).

Keywords: Oat, bromatology, conserved forage, crude protein, triticale

\section{Ensilajes pre-secados de cereales de invierno en estadio de prefloración: Una revisión}

RESUMEN. La producción de ensilaje pre seca de mejor costo beneficio combinando alta producción, valor nutricional y costo de producción son fundamentales para la estabilidad en sistemas de producción. Teniendo en cuenta este contexto, los cereales de invierno ganan destaque porque son excelentes para la oferta In natura es decir, en pastoreo, además de la capacidad de conservar su excedente. El sur del país todavía tiene muchas áreas inactivas en el período de invierno, las zonas donde se cultiva maíz, temporada tras temporada, siendo esto otros puntos favorables para la producción de ese 
alimento,aumentando la rentabilidad y la rotación de la misma. Entre los cultivos de invierno, más utilizadas para hacer ensilaje pre-seca se destaca la avena negra (Avena strigosa), avena blanca (Avena sativa), cebada (Hordeum vulgare), trigo (Triticum aestivum), centeno (Secale cereale) y triticale (X Triticosecale).

Palabras clave: Avena, bromatología, proteína cruda del forraje conservado, triticale

\section{Introdução}

Por definição, silagem pré-secada é o processo de conservação da forragem resultante da fermentação anaeróbica, em que, basicamente carboidratos solúveis são convertidos em ácidos orgânicos pela ação de microrganismos que, em ambiente ideal, se proliferam e proporcionam condições adequadas à conservação, preservando seu valor nutritivo (Bolsen, 1995, McDonald, 1981). Todavia, como o próprio nome faz menção, a forragem deve passar por um período de desidratação ou secagem antes da ensilagem.

A região Sul do Brasil tem em sua essência a produção de bovinos a pasto, o que lhe é permitido devido ao alto potencial produtivo e as ótimas condições de cultivo dos cereais de inverno (Oliveira, 2009).

De maneira pontual, o estado do Paraná possui características climáticas ideais para o cultivo de diversas espécies forrageiras durante todo o ano (Bortolini et al., 2004). Todavia, é inevitável a passagem por um período de vazio forrageiro no início do inverno, onde as forragens de verão já completaram seu ciclo e as de inverno ainda não se estabeleceram (Meinerz et al., 2011b).

Com vistas à manutenção e ampliação da produção de leite ou carne nesses períodos de escassez de forrageira, não se deve abrir mão de estratégias nutricionais como a utilização de alimentos conservados. No entanto, um sistema produtivo profissional trata como obrigatório a utilização de volumosos alternativos durante todo o ano, e não somente em períodos de escassez de pastagens. No tocante a produção desses alimentos, todas as forragens são potencialmente conserváveis e mantedoras de nutrientes, com mais ou menos proteínas, carboidratos solúveis e fibras digestíveis (Jobim et al., 2010).

Cabe ressaltar que, o estádio de préflorescimento dos cereais de inverno em geral alia elevados teores de proteína bruta e fibra de alta digestibilidade; porém, é nessa mesma fase onde o material encontra-se com baixo nível de matéria seca (Borreani et al., 2007), necessitando da présecagem.

Dentre os alimentos passiveis de conservação, o milho é o mais utilizado (Bernardes and Rêgo, 2014) por ser extremamente energético. Em contrapartida, os cereais de inverno possuem um alto teor de proteína, principalmente na fase vegetativa (Fontaneli et al., 2009). Portanto, um não substitui o outro, mas sim, cada qual tem uma função distinta dentro de cada dieta.

Os cultivares invernais apresentam alta umidade e elevado teor de proteína, quando ensilados em estádio pré-florescimeto, características que gerariam tamponamento do material ensilado. Portanto, a forma de silagem pré-secada é a mais adequada para conservação com qualidade do material (Zamarchi et al., 2014), uma vez que é caracterizado pelo índice mais elevado de matéria seca ( 40 a $65 \%$ ) e tem seu teor proteico diluído na planta.

A produção de silagem pré-secada de melhor custo benefício aliando alta produção, valor nutricional e custo de produção são fundamentais para sobrevivência no sistema produtivo. (Brondani et al., 2000). Nesse contexto, os cereais de inverno ganham destaque por serem excelentes para a oferta in natura, ou seja, em pastejo e terem ainda a possibilidade de conservação de seu excedente.

O Sul do Brasil ainda comporta muitas áreas ociosas no período de inverno, áreas onde é cultivado milho, safra após safra, sendo esses, outros pontos favoráveis a confecção desse alimento, aumentando a lucratividade e a rotatividade da mesma.

Dentre as culturas de inverno mais utilizadas para o feitio de silagem pré-secada destacam-se a aveia preta (Avena strigosa), aveia branca (Avena sativa), cevada (Hordeum vulgare), trigo (Triticum aestivum), centeio (Secale cereale) e o triticale (X Triticosecale).

No entanto, a quantidade e a qualidade da forragem produzida pelos cereais de inverno são dependentes de diversos fatores, como a variabilidade entre as espécies, entre genótipos de mesma espécie e sua adaptabilidade às diferentes condições edafoclimáticas (Meinerz et al., 2011a). Com isso, o objetivo dessa revisão bibliográfica é tratar da silagem pré-secada de cereais de inverno 
em estádio de pré-florescimento.

\section{Visão geral}

Durante o período hibernal, a região Sul do Brasil é privilegiada por poder se beneficiar de fatores climáticos propícios para produção de forrageiras $\mathrm{C}_{3}$, contando com temperatura e pluviometria favorável para o desenvolvimento das mesmas (Köppen and Geiger, 1928).

Desse modo, a produção de bovinos a pasto vem se tornando uma prática cada vez mais evidente, principalmente nessas épocas mais frias do ano, uma vez que as culturas invernais podem ser manejadas com duplo propósito (Moreira et al., 2005), e os grãos advindos dessas culturas temperadas têm baixa competitividade no mercado internacional. Então, vê-se na engorda de bovinos uma grande oportunidade de aumentar a lucratividade da propriedade (Fontaneli et al. 2000).

Segundo Bumbieris Júnior et al. (2011), além se serem passiveis de pastejo, o excedente dessas culturas podem ser destinados à produção de silagem pré-secada. Dessa forma ter-se-á alimento estocado para outras épocas, além de diminuir a concorrência com culturas de verão, uma vez que para produção de silagem pré-secada, a mesma é colhida antes do fechamento do seu ciclo normal.

Por definição, silagem é o processo de conservação da forragem resultante da fermentação anaeróbica, em que, basicamente carboidratos solúveis são convertidos em ácidos orgânicos pela ação de microrganismos que, em ambiente ideal, se proliferam e proporcionam condições adequadas à conservação, preservando seu valor nutritivo (Woolford and Pahlow, 1998, McDonald, 1981).

Cabe ressaltar que a desidratação de forragens para ensilagem é capaz de aumentar a razão ácido lático:acético, reduzir a produção de amônia e restringir a produção de ácido butírico, além de haver economia de carboidratos solúveis, diminuir a solubilização do nitrogênio e evitar a produção de efluentes (Berto and Mühlbach, 1997). Tais respostas estão relacionadas à redução de processos indesejáveis que podem ocorrer durante o processo de ensilagem, que surgem com a demora na queda do $\mathrm{pH}$ ou então a alta atividade de água.

No Brasil, a utilização dessas silagens présecadas de forrageiras temperadas são tidas como uma alternativa de fornecimento de volumoso de qualidade em períodos de escassez de pastagens (Zamarchi et al., 2014). Todavia, na Europa, os cereais de inverno vêm passando do status de culturas forrageiras estratégicas para épocas de escassez de alimento, a um status de cultura forrageira basal das dietas, constituindo uma verdadeira estratégia no planejamento forrageiro (Lemaire et al., 2006).

De maneira pontual, as forragens tropicais $\left(\mathrm{C}_{4}\right)$ são caracterizadas pelo seu alto teor energético e terem nível de umidade menor no momento da ensilagem. De forma contrária, as forragens de clima temperado $\left(\mathrm{C}_{3}\right)$ possuem um elevado conteúdo proteico e alta umidade em comparação às $\mathrm{C}_{4}$, o que dificultaria o processo fermentativo pela capacidade tampão (Bumbieris Júnior et al., 2011).

A propósito, sabe-se que para uma ótima conservação do material ensilado é fundamental manter valores de $\mathrm{pH}$ entre 3,8 e 4,2 (Ferreira et al., 2001). Caso esses valores não sejam alcançados por algum motivo, após a abertura do silo, microrganismos indesejáveis tornar-se-ão metabolicamente ativos, produzindo calor e consumindo nutrientes (Ranjit and Kung, 2000).

Forragens quando ensiladas com menos de $21 \%$ de matéria seca correm sérios riscos de sofrer fermentação secundária no silo (McDonald, 1981). Portanto, para se produzir uma silagem de cultivares invernais de alta qualidade, aconselhase o pré-murchamento do material antes de ensilálo propriamente dito (Zamarchi et al., 2014). Além disso, o pré-murchamento da forragem reduz a produção de efluentes, decorrentes da ruptura celular e extravasamento de conteúdo citoplasmático durante o período de armazenamento, o qual carreia junto a si nutriente dos alimentos (Schmidt et al., 2011).

Do outro lado tem-se ainda a possibilidade de produção de fenos, porém, nesse caso existe o risco de se deparar com chuvas durante o processo de secagem ou enfardamento, além ainda, das maiores perdas de açucares e demais nutrientes através de lixiviação e respiração celular (Rotz and Muck, 1994) pelo maior tempo a campo.

Segundo McDonald (1981), o teor de matéria seca da forragem além de afetar o perfil fermentativo, está relacionado também ao potencial de ingestão e a eficiência de utilização de nutrientes pelo animal. Nesse contexto, nota-se que a escolha do modo de conservação e sua destinação estão diretamente relacionadas ao tipo 
de cultura. Independentemente da forma de conservação, o objetivo chave é reduzir a respiração celular dos vegetais e a atividade microbiana aeróbia ao longo do processo de estocagem (Rotz and Muck, 1994). Caso isso não ocorra, perdas quali e quantitativas podem chegar a níveis catastróficos. Os indicadores da deterioração aeróbica mais comumente observados são o desenvolvimento de mofos, aquecimento espontâneo, perda de matéria seca, aumento das concentrações de fibra e redução da digestibilidade dos nutrientes (Bolsen, 1995).

Todavia, eficazmente devem-se mensurar as perdas do material através da estabilidade aeróbia do mesmo. Essa por definição é a resistência que a massa ensilada oferece a deterioração após ser exposta ao ar (Tres et al., 2014). Vários são os fatores que interferem na estabilidade aeróbia do material, como a concentração de microrganismos aeróbios na silagem, o tempo de exposição ao oxigênio até a completa vedação do silo, a temperatura ambiente, além das características da forragem utilizada (Bolsen, 1995).

Segundo Meinerz et al. (2011b), todas as espécies e genótipos apresentam condições para serem ensiladas e produzirem silagens com perfil fermentativo desejável, porém, cada uma possui características produtivas e nutricionais distintas (Tabela 1).

Tabela 1. Características produtivas e nutricionais de diferentes forragens pré-ensiladas

\begin{tabular}{|c|c|c|c|c|c|}
\hline Autores & $\begin{array}{l}\mathrm{PB} \\
(\%)\end{array}$ & $\begin{array}{l}\text { FDN } \\
(\%)\end{array}$ & $\begin{array}{c}\text { FDA } \\
(\%)\end{array}$ & $\begin{array}{c}\text { Produção de MS } \\
\text { ha }^{-1}\end{array}$ & $\begin{array}{c}\text { Altura de planta } \\
(\mathrm{cm})\end{array}$ \\
\hline & \multicolumn{5}{|c|}{ Aveia preta } \\
\hline Lehmen et al. (2014) & 6,0 & 74,3 & 43,4 & 9.500 & 123 \\
\hline Meinerz et al. (2011a) & 6,2 & 70,8 & 40,4 & 9.075 & 116 \\
\hline \multirow[t]{2}{*}{ Fontaneli et al. (2009) } & 10,2 & 67,3 & 39,4 & 5.419 & 112 \\
\hline & \multicolumn{5}{|c|}{ Aveia branca } \\
\hline Lehmen et al. (2014) & 7,6 & 64,1 & 37,0 & 9.713 & 101 \\
\hline Meinerz et al. (2011a) & 6,9 & 68,3 & 39,9 & 11.913 & 114 \\
\hline \multirow[t]{2}{*}{ Fontaneli et al. (2009) } & 9,5 & 58,3 & 32,0 & 6.159 & 111 \\
\hline & \multicolumn{5}{|c|}{ Cevada } \\
\hline Lehmen et al. (2014) & 8,4 & 59,6 & 30,7 & 6.500 & 56 \\
\hline Meinerz et al. (2011a) & 7,4 & 58,2 & 32,5 & 6.648 & 72 \\
\hline \multirow[t]{2}{*}{ Fontaneli et al. (2009) } & 7,8 & 61,4 & 31,8 & 4.628 & 73 \\
\hline & \multicolumn{5}{|c|}{ Trigo } \\
\hline Lehmen et al. (2014) & 8,0 & 65,4 & 33,8 & 10.937 & 79 \\
\hline Meinerz et al. (2011a) & 7,3 & 63,1 & 35,4 & 9.278 & 67 \\
\hline \multirow[t]{2}{*}{ Fontaneli et al. (2009) } & 8,0 & 64,6 & 35,6 & 5.091 & 77 \\
\hline & \multicolumn{5}{|c|}{ Centeio } \\
\hline Lehmen et al. (2014) & 6,8 & 73,7 & 40,4 & 13.448 & 160 \\
\hline Meinerz et al. (2011a) & 6,3 & 72,1 & 45,9 & 9.058 & 142 \\
\hline \multirow[t]{2}{*}{ Fontaneli et al. (2009) } & 9,0 & 66,7 & 37,3 & 9.721 & 142 \\
\hline & \multicolumn{5}{|c|}{ Triticale } \\
\hline Lehmen et al. (2014) & 7,9 & 63,2 & 28,9 & 9.859 & 105 \\
\hline Meinerz et al. (2011a) & 8,5 & 62,7 & 37,6 & 9.267 & 94 \\
\hline Fontaneli et al. (2009) & 8,1 & 66,1 & 35,6 & 5.375 & 99 \\
\hline
\end{tabular}

Fonte: os autores

O potencial forrageiro de um cultivar é dimensionado tanto pelo seu valor nutritivo quanto pela sua produtividade. Floss et al. (2007) trabalhando com aveia branca para silagem em estádio de pré-florescimento, sob diferentes tempos de corte, obteve para 112 dias de ciclo uma produtividade de $10.080 \mathrm{~kg}$ de $\mathrm{MS} \mathrm{ha}^{-1}$, e para 126 dias $12.240 \mathrm{~kg} \mathrm{MS} \mathrm{ha}^{-1}$, ou seja, produtivamente mostrou-se mais viável prolongar o ciclo da cultura em questão. Deve-se destacar que os 
autores encontraram para ambos os ciclos a mesma altura média de planta $(126 \mathrm{~cm})$, que mostra também, a importância de se conhecer a cultivar com a qual se trabalha.

Em relação à cultura da aveia preta, a mesma tem baixo valor de grãos para a indústria, então, busca-se com essa cultura uma alternativa lucrativa. Viu-se assim, na sua alta resistência a doenças um ponto favorável a sua utilização como pastagem, sendo a a mais utilizada para tal fim.

Fontaneli et al. (2009) obtiveram para cultura da aveia preta, como forragem verde, produtividade média de $5.989 \mathrm{~kg}$ de $\mathrm{MS} \mathrm{ha}^{-1}$, e teor de FDN de 50,6\%, menores valores entre as demais culturas estudadas no mesmo trabalho. Porém, a digestibilidade da matéria seca da mesma sobressaiu todas as outras, com valor de $70,5 \%$. Todavia, quando a mesma foi ensilada, o material resultante mostrou valores de FDN de $67,3 \%$, o que diminui consideravelmente a digestibilidade da matéria seca $(58,2 \%)$.

Em relação à silagem pré-secada de cevada, a mesma vem ganhando espaço como parte estratégica das dietas de bovinos devido a sua alta qualidade nutricional. Segundo Rojas and Catrileo (2000), a qualidade da silagem de cevada diminui de acordo com o avanço da maturidade da planta motivado pelo aumento da percentagem de colmo. Todavia, segundo os mesmos autores, com o avanço da maturidade se ganha em produção de matéria seca, tanto por área quanto em percentagem na planta. Entretanto, esse incremento de matéria seca juntamente com seu alto teor de carboidratos solúveis pode gerar uma maior instabilidade aeróbia na abertura do silo.

A cultura do centeio como pastagem e/ou alimento conservado vêm se destacando pela sua alta resistência as baixas temperaturas e a sua tolerância a solos pobres (Del Duca et al., 1999).

Lehmen et al. (2014) avaliando o rendimento produtivo da aveia preta (Avena strigosa), aveia branca (Avena sativa), cevada (Hordeum vulgare), trigo (Triticum aestivum), centeio (Secale cereale) e triticale ( $X$ Triticosecale), obtiveram o menor valor de produtividade para a cultura da cevada (BRS Cauê), com rendimento de $6.500 \mathrm{~kg}$ de MS $\mathrm{ha}^{-1}$. De forma contrária, o maior rendimento encontrado foi para a cultura do centeio (BRS Serrano), com $13.448 \mathrm{~kg}$ de MS ha-1. De acordo com os autores, a explicação para tal diferença estaria no nível de insolação recebida por cada cultura durante seu ciclo, visto que a cevada foi colhida com 139 dias e o centeio com 170 dias. Quanto à cultura do trigo, essa apresenta grande importância, sendo a segunda mais plantada no mundo, ficando atrás apenas da cultura do milho (Bumbieris Júnior et al., 2011). Os trigos destinados a produção forrageira, possuem uma produção de matéria seca por área maior em relação aos trigos com destino a produção de grãos. Porém, por terem maior porte, são mais susceptíveis ao acamamento (Carletto et al., 2015) e devem ter altura de planta e ciclos ideais para evitar tal problemática.

Ao trabalharem com duas cultivares de trigo de duplo propósito, Lehmen et al. (2014) obtiveram produção de $10.937 \mathrm{~kg}$ de $\mathrm{MS} \mathrm{ha}^{-1}$ para a cultivar BRS Tarumã e $8.688 \mathrm{~kg}$ de MS ha ${ }^{-1}$ para a cultivar BRS Umbu, ambas colhidas em estádio de préflorescimento. Nota-se que as diferentes espécies forrageiras invernais apresentam diferenças entre si, seja no ciclo, capacidade de crescimento e /ou produtivo. Por fim, porém não menos importante, a cultura do triticale possui alta tolerância ao frio, stress hídrico e doenças, mostrando-se como uma opção a ser estudada como forrageira para ensilagem (Kloster et al., 2013). Ademais, o triticale pode ser utilizado na forma de silagem pré-secada, silagem, feno, grão úmidos, grãos secos e ainda na forma de pastagem (Lopes et al., $\underline{2008)}$.

\section{Silagem pré-secada}

Existem diversos métodos de conservação de forragens para alimentação animal, todos visando manter a qualidade nutricional do alimento o mais próximo possível do momento da colheita. As maneiras mais utilizadas para conservação de forragens são sob a forma de silagens, caracterizadas por teores de matéria seca variando entre 30 e $40 \%$, fenos, sendo esses alimentos mais secos, acima de $80 \%$ de matéria seca, isentos de processo fermentativo, e a terceira forma de conservação, menos utilizada quando comparada as outras duas, são as silagens pré-secadas, caracterizadas por teores de matéria seca intermediária aos dois primeiros (Bernardes and Rêgo, 2014).

A silagem pré-secada é um método de conservação químico, caracterizado por um período de pré-secagem da forragem a campo após o seu corte. Após atingir níveis ideais de umidade, a forragem é ensilada em ambiente anaeróbio a fim de criar condições para uma perfeita fermentação lática (Bragachini et al., 2008), 
resultando em uma conservação adequada do alimento.

Bragachini et al. (2008) enfatizam que a principal vantagem em se confeccionar silagem pré-secada está relacionada ao menor tempo de exposição do material ao ambiente, quando comparado ao feno, e dessa forma, o risco em enfrentar condições climáticas adversas são menores. Sabe-se que na região Sul do Brasil as temperaturas são amenas, a umidade reativa do ar é alta, e as chuvas são frequentes, o que aumenta o risco de danos às forragens expostas ao tempo (Woolford and Pahlow, 1998, McDonald, 1981).

De forma pontual, a desidratação das forragens é de caráter multifatorial, dentre os quais cabe destacar os fatores relacionados ao ambiente, como a radiação solar, pressão de vapor, velocidade do vento e a chuva (McDonald, 1981). A radiação solar contribui significativamente na forragem exposta, estimulando a evaporação da água ao ambiente, fase em que a velocidade do vento atua expressivamente carreando as gotículas mencionadas. Já a pressão de vapor incentiva o deslocamento da água do meio extracelular ao ambiente, e ainda de acordo com o mesmo autor, a ocorrência de chuva traz efeito negativo ao material colhido por aumentar o teor de umidade. É importante salientar que a desidratação da forragem tem o objetivo de restringir a extensão da fermentação durante $o$ processo de conservação, além de inibir fermentações secundárias (Woolford and Pahlow, 1998, McDonald, 1981). Ademais, a desidratação de forragens para ensilagem é capaz de aumentar a razão ácido lático:acético, reduzir a produção de amônia e restringir a produção de ácido butírico, além de haver economia de carboidratos solúveis, diminuir a solubilização do nitrogênio e evitar a produção de efluentes (Berto and Mühlbach, 1997). Tais respostas são relacionadas a redução de processos indesejáveis que podem ocorrer durante o processo de ensilagem, que surgem com a demora na queda do $\mathrm{pH}$ ou então a alta atividade de água.

Segundo Jobim et al. (2007), a desidratação se torna importante para forragens cujo teor de matéria seca encontre-se abaixo de $28 \%$ no momento do corte. Além disso, quando se trata de forragens hibernais, o elevado teor de proteína bruta e cinzas presente nas mesmas, podem gerar um efeito tamponante no material ensilado, o que, segundo os mesmos autores, torna a pré-secagem ainda mais indispensável.
Cabe ressaltar que, o estádio de préflorescimento dos cereais de inverno em geral alia elevados teores de proteína bruta e fibra de alta digestibilidade, porém, é nessa mesma fase onde o material encontra-se com baixo nível de matéria seca (Borreani et al., 2007), necessitando da présecagem. Traçando um paralelo, Bumbieris Júnior et al. (2011) afirmam que as forragens tropicais, com destaque ao milho são caracterizadas pelo seu alto teor energético e terem nível de umidade menor no momento da ensilagem. De forma contrária, as forragens de clima temperado possuem um elevado conteúdo proteico e alta umidade em comparação às tropicais, o que dificultaria o processo fermentativo pela capacidade tampão.

Além disso, dados disponíveis na literatura relatam a importância da pré-secagem de forragens úmidas antes da ensilagem, principalmente, em função da redução na produção de efluente e no impacto restritivo da fermentação. No entanto, a diminuição da umidade proporciona benefícios na ensilagem, desde que atinja pelo menos $30 \%$ de matéria seca (Woolford and Pahlow, 1998), associado a uma rápida taxa de secagem (Dawson et al., 1999).

\section{Estádio de colheita de cereais de inverno para silagem pré-secada}

Quando se trata do fornecimento de cereais de inverno aos ruminantes, o estádio fenológico da cultura gera grandes discussões. É fato consumado que as mudanças na composição química das forragens são de caráter multifatorial e tal fato indica diferentes recomendações de estádios de maturação na ensilagem.

De acordo com Buxton et al. (1996) existe uma variação entre espécies de cereais de inverno tão grande quanto a variação entre genótipos da mesma espécie, além disso, os autores relatam que o estádio de colheita interfere diretamente na qualidade nutricional do alimento. Ao passo que a planta avança em estádios de maturação a produção de matéria seca tende a aumentar (David et al., 2010, Beck et al., 2009); porém, ocorre redução nos teores de proteína bruta (Fontaneli et al., 2009). Coblentz and Walgenbach (2010) observaram que as reduções nos teores proteína digestíveis com o avanço do estádio de maturação, foram compensadas pelo aumento nos teores de carboidratos não fibrosos digestíveis.

De maneira geral, os cereais de inverno possuem elevado valor nutritivo, tanto no estádio 
de pré-florescimento quanto no estádio de grão farináceo, porém, cada qual com suas peculiaridades estruturais e químicas. O estádio de pré-florescimento é caracterizado pela elevada concentração de proteína bruta, baixo teor de matéria seca e fibra de alta digestibilidade (Filya, $\underline{2003}$ ). Já o estádio de grão farináceo se torna um alimento mais calórico por possuir alta concentração de amido na matéria seca, no entanto, perde-se a qualidade da fibra (Floss et al., 2007). Filya (2003) avaliando cereais de inverno em diferentes estádios observaram significância para digestibilidade da FDN e proteína bruta ( $42,2 \%$ contra $34,9 \%$ e $7,3 \%$ contra $5,9 \%$, para os estádios de pré-florescimento e grão farrináceo, respectivamente). No entanto, o autor relata que o estádio de grão farináceo apresenta maior digestibilidade da matéria seca $(67,6 \%$ contra $58,5 \%$ ), dado o maior teor de amido presente nessa fase.

Tais resultados corroboram com os observados por Weinberg and Chen (2013), os quais relataram superioridade do potencial digestivo da FDN da forragem e da silagem de trigo no estádio de préflorescimento quando comparado ao estádio de grão farináceo, porém, menor digestibilidade da matéria seca para o primeiro. Já Wallsten and Martinsson (2009) observaram que o avanço do estádio de maturação da cevada proporcionou redução na FDN e na digestibilidade da matéria seca. Da mesma forma, Wallsten et al. (2010) avaliando silagens de aveia e de cevada, relataram que $\mathrm{o}$ avanço da maturidade proporcionou decréscimos nas digestibilidades da matéria orgânica.

Os resultados relatados na literatura quanto ao estádio de maturação de cereais de inverno são inconsistentes. Tais respostas podem ser justificadas, dentre tantas variáveis, pela diferença nas cultivares utilizadas, participações dos constituintes da planta, taxas de secagens distintas e teor matéria seca na ensilagem.

\section{Conclusão}

A utilização de alimentos conservados, como a silagem pré-secada de cereais de inverno, vêm se tornando uma ferramenta para manutenção da produtividade do sistema pecuário intensivo. No entanto, a quantidade e a qualidade da forragem produzida pelos cereais de inverno são dependentes de diversos fatores, dos quais cabe destacar a variabilidade entre as espécies, entre genótipos de mesma espécie, e suas adaptabilidades às diferentes condições ambientais.

\section{Referências Bibliográficas}

Beck, P. A., Stewart, C. B., Gray, H. C., Smith, J. L. \& Gunter, S. A. 2009. Effect of wheat forage maturity and preservation method on forage chemical composition and performance of growing calves fed mixed diets. Journal of Animal Science, 87, 4133-4142.

Bernardes, T. F. \& Rêgo, A. C. 2014. Study on the practices of silage production and utilization on Brazilian dairy farms. Journal of Dairy Science, 97, 1852-1861.

Berto, J. L. \& Mühlbach, P. R. F. 1997. Silagem de aveia preta no estádio vegetativo, submetida à ação de inoculantes e ao efeito do emurchecimento. Revista Brasileira de Zootecnia, 26, 651-658.

Bolsen, K. K. 1995. Silage: basic principles. Forages, 5, 163-176.

Borreani, G., Giaccone, D., Mimosi, A. \& Tabacco, E. 2007. Comparison of hay and haylage from permanent alpine meadows in winter dairy cow diets. Journal of Dairy Science, 90, 5643-5650.

Bortolini, P. C., Sandini, I., Carvalho, P. C. F. \& Moraes, A. 2004. Cereais de inverno submetidos ao corte no sistema de duplo propósito. Revista Brasileira de Zootecnia, 33, 45-50.

Bragachini, M., Cattani, P., Gallardo, M. \& Peiretti, J. 2008. Forrajes conservados de alta calidad y aspectos relacionados al manejo nutricional. Instituto Nacional de Tecnología Agropecuaria.

Brondani, I. L., Alves Filho, D. C., Bernardes, R. A. C. \& Restle, J. 2000. Silagem de alta qualidade para bovinos. In: Restle, j. (ed.) Eficiência na produção de bovinos de corte. Santa Maria: Universidade Federal de Santa Maria. Universidade Federal de Santa Maria, Santa Maria, Rio Grande do Sul.

Bumbieris Júnior, J. R., Oliveira, V. H., Jobim, C. C., Barbosa, M. A. A. F., Castro, L. M. \& Barrero, R. P. 2011. Perspectivas para uso de silagem de cereais de inverno no Brasil. In: Jobim, C. C. (ed.) Simpósio de produção e utilização de forragens conservadas. Universidade Estadual de Maringá, Maringá.

Buxton, D. R., Mertens, D. R. \& Fisher, D. S. 1996. Forage quality and ruminant utilization. Cool-Season Forage Grasses, 1, 229-266. 
Carletto, R., Neumann, M., Leão, G. F. M., Horst, E. H. \& Askel, E. J. 2015. Efeito do manejo de cortes sucessivos sobre a produção e qualidade de grãos de trigo duplo propósito. Revista Acadêmica de Ciências Animal, 13, 127-135.

Coblentz, W. K. \& Walgenbach, R. P. 2010. Fall growth, nutritive value, and estimation of total digestible nutrients for cereal-grain forages in the north-central United States. Journal of Animal Science, 88, 383-399.

David, D. B., Nörnberg, J. L., Azevedo, E. B., Brüning, G., Kessler, J. D. \& Skonieski, F. R. 2010. Nutritional value of black and white oat cultivars ensiled in two phenological stages. Revista Brasileira de Zootecnia, 39, 14091417.

Dawson, L. E. R., Ferris, C. P., Steen, R. W. J., Gordon, F. J. \& Kilpatrick, D. J. 1999. The effects of wilting grass before ensiling on silage intake. Grass and Forage Science, 54, 237-247.

Del Duca, L. J. A., Guarienti, E. M., Fontaneli, R. S. \& Zanotto, D. L. 1999. Influência de cortes simulando pastejo na composição química de grãos de cereais de inverno. Pesquisa Agropecuária Brasileira, 34, 1607-1614.

Ferreira, J. J., Cruz, J. C., Pereira Filho, J. A. \& Rodrigues, J. A. S. 2001. Estágio de maturação ideal para ensilagem do milho e do sorgo. In: Cruz, J. C., Pereira Filho, I. A., Rorigues, J. A. S. \& Ferreira, J. J. (eds.) Produção e utilização de silagem de milho e sorgo. EMBRAPA, Sete Lagoas.

Filya, I. 2003. Nutritive value of whole crop wheat silage harvested at three stages of maturity. Animal Feed Science and Technology, 103, 8595.

Floss, E. L., Palhano, A. L., Soares Filho, C. V. \& Premazzi, L. M. 2007. Crescimento, produtividade, caracterização e composição química da aveia branca. Acta Scientiarum. Animal Sciences, 29, 1-7.

Fontaneli, R. S., Ambrosi, I., Santos, H. P., Ignaczak, J. C. \& Zoldan, S. M. 2000. Análise econômica de sistemas de produção de grãos com pastagens anuais de inverno, em sistema plantio direto. Pesquisa Agropecuária Brasileira, 35, 2129-2137.

Fontaneli, R. S., Fontaneli, R. S., Santos, H. P., Nascimento Junior, A., Minella, E. \& Caierão, E. 2009. Rendimento e valor nutritivo de cereais de inverno de duplo propósito: forragem verde e silagem ou grãos. Revista
Brasileira de Zootecnia, 38, 2116-2120.

Jobim, C. C., Branco, A. F., Gai, V. F., Calixto Junior, M. C. \& Santos, G. T. 2010. Quality of high moisture corn grain silage with addition of raw soybean grains and parameters of partial and total digestibility in cattle. Qualidade $d a$ silagem de grãos de milho com adição de soja crua e parâmetros de digestibilidade parcial e total em bovinos, 62, 107-115.

Jobim, C. C., Nussio, L. G., Reis, R. A. \& Schmidt, P. 2007. Avanços metodológicos na avaliação da qualidade da forragem conservada. Revista Brasileira de Zootecnia, 36, 101-119.

Kloster, A. M., Bainotti, C., Cazorla, C., Amigone, M. A., Donaire, G. \& Baigorria, T. 2013. Triticale. Un cultivo invernal plástico y multifuncional. Revista Técnica de la Asociación Argentina de Productores de Siembra Directa, 1, 50-56.

Köppen, W. \& Geiger, R. 1928. Klimate der Erde. Gotha: Verlag Justus Perthes. Wall-map $150 \mathrm{~cm} \times 200 \mathrm{~cm}$.

Lehmen, R. I., Fontaneli, R. S., Fontaneli, R. S. \& Santos, H. P. d. 2014. Rendimento, valor nutritivo e características fermentativas de silagens de cereais de inverno. Ciência Rural, 44, 1180-1185.

Lemaire, G., Delaby, L., Fiorelli, J. L. \& Micol, D. 2006. Adaptations agronomiques au risque de sécheresse: Systèmes fourragers et élevage. Rapport d'Expertise INRA Sécheresse et agriculture: réduire la vulnérabilité de l'agriculture à un risque accru de manque d'eau. INRA, Paris.

Lopes, F. C., Silva, J. O., Lanes, E. C., Duque, A. C. \& Ramos, C. R. 2008. Valor nutricional do triticale (Triticosecale Wittimack) para uso como silagem na Zona da Mata de Minas Gerais. Arquivo Brasileiro de Medicina Veterinaria e Zootecnia, 60, 1484-1492.

McDonald, P. 1981. The biochemistry of silage. John Wiley \& Sons, Ltd., Oklahoma: Marlow.

Meinerz, G. R., Olivo, C. J., Fontaneli, R. S., Nörnber, J. L., Agnolin, C. A., Scheibler, R. B., Horst, T. \& Fontaneli, R. S. 2011a. Valor nutritivo da forragem de genótipos de cereais de inverno de duplo propósito. Revista Brasileira de Zootecnia, 40, 1173-1180.

Meinerz, G. R., Olivo, C. J., Viégas, J., Nörnberg, J. L., Agnolin, C. A., Scheibler, R. B., Horst, T. \& Fontaneli, R. S. 2011 b. Silagem de cereais 
de inverno submetidos ao manejo de duplo propósito. Revista Brasileira de Zootecnia, 40, 2097-2104.

Moreira, F. B., Prado, I. N., Souza, N. E., Matsushita, M., Mizubitu, I. Y. \& Macedo, L. M. A. 2005. Desempenho animal e características da carcaça de novilhos terminados em pastagem de aveia preta, com ou sem suplementação energética. Acta Scienciarum. Animal Sciences, 27, 469-473.

Oliveira, J.T. 2009. Distribuição estacional de forragem, valor Nutritivo e rendimento de grãos de cereais de Inverno de duplo propósito. Departamento de Agronomia. Universidade de Passo Fundo, Rio Grande do Sul, Passo Fundo.

Ranjit, N. K. \& Kung, L. 2000. The effect of Lactobacillus buchneri, Lactobacillus plantarum, or a chemical preservative on the fermentation and aerobic stability of corn silage. Journal of Dairy Science, 83, 526-535.

Rojas, G. \& Catrileo, S. 2000. Evaluación de ensilaje de cebada en tres estados de corte en la engorda invernal de novillos. Agricultura Técnica, 60, 370-378.

Rotz, C. A. \& Muck, R. E. 1994. Changes in forage quality during harvest and storage. In: Fahey, G. C., Collins, M., Mertens, D. R. \& Moser, L. E. (eds.) Forage quality, evaluation, and utilization. American Society of Agronomy, Madison, USA.

Schmidt, P., Novinski, C. O. \& Junges, D. 2011. Riscos ambientais oriundos de compostos orgânicos voláteis e do efluente produzido por silagens. Simpósio sobre produção de forragens conservadas, 4, 251-270.

Tres, T. T., Jobim, C. C., Rossi, R. M., Silva, M.
S. \& Poppi, E. C. 2014. Silagem de grãos de milho, com adição de soja: estabilidade aeróbia e desempenho de vacas leiteiras. Revista Brasileira de Saúde e Produção Animal, 15, 248-260.

Wallsten, J., Bertilsson, J., Nadeau, E. \& Martinsson, K. A. 2010. Digestibility of whole-crop barley and oat silages in dairy heifers. Animal, 4, 432-438.

Wallsten, J. \& Martinsson, K. 2009. Effects of maturity stage and feeding strategy of whole crop barley silage on intake, digestibility and milk production in dairy cows. Livestock Science, 121, 155-161.

Weinberg, Z. G. \& Chen, Y. 2013. Effects of storage period on the composition of whole crop wheat and corn silages. Animal Feed Science and Technology, 185, 196-200.

Woolford, M. K. \& Pahlow, G. 1998. The silage fermentation. Springer, New York.

Zamarchi, G., Pavinato, P. S., Menezes, L. F. G. \& Martin, T. N. 2014. Silage of white oat under nitrogen fertilization and pre-wilting. Semina: Ciências Agrárias, 35, 2185-2196.

\section{Article History:}

Received 19 December 2016

Accepted 4 February 2017

Available on line 24 March 2017

License information: This is an open-access article distributed under the terms of the Creative Commons Attribution License 4.0, which permits unrestricted use, distribution, and reproduction in any medium, provided the original work is properly cited 